\title{
DNA methylation patterns of behavior-related gene promoter regions dissect the gray wolf from domestic dog breeds
}

Zsofia Banlaki, $1, *$

Phone +36206660138

Email banlaki.zsofia@med.semmelweis-univ.hu

Giulia Cimarelli, 2,3,4, 7,8 Affiliations "7" and "8" are actually a part of affiliation "2" in the present case, so data from "7" and "8" should be merged into affiliation "2".

The reason is that authors $\mathrm{G}$ Cimarelli and $\mathrm{Z}$ Viranyi are actually affiliated to the Messerli Research Institute (in addition to the Wolf Science Center). However, Messerli Institute is in close partnership with both the University of Veterinary Medicine, Vienna, the Medical University of Vienna and the University of Vienna; thus in all cases when the Messerli Institute is indicated as an affiliation, these three universities should be indicated as well. As the Messerli Institute is physically located within premises of the University of Veterinary Medicine, Vienna, address of the latter is indicated (Veterinärplatz 1, 1210 Vienna, Austria).

Thus, the correct text for affiliation "2" is: Comparative Cognition, Messerli Research Institute, University of Veterinary Medicine, Vienna, Medical University of Vienna, University of Vienna, Veterinärplatz 1, 1210 Vienna, Austria.

Accordingly, affiliations "7" and "8" should be deleted.

Zsofia Viranyi, $2,3,7,8$

Eniko Kubinyi, 5,6

Maria Sasvari-Szekely, ${ }^{1}$

Zsolt Ronai, 1 
${ }^{1}$ Department of Medical Chemistry, Molecular Biology and Pathobiochemistry, Semmelweis University, Tüzoltó utca 3747, Budapest, 1094 Hungary

2 Comparative Cognition, Messerli Research Institute, University of Veterinary Medicine, Vienna, Veterinärplatz 1, 1210 Vienna, Austria

3 Wolf Science Center, Dörfles 48, 2115 Ernstbrunn, Austria

4 Department of Cognitive Biology, University of Vienna, Althanstrasse 14, 1190 Vienna, Austria

5 MTA-ELTE Comparative Ethology Research Group, Hungarian Academy of Sciences, Pázmány Péter sétány

1/C, Budapest, 1117 Hungary

6 Department of Ethology, Eötvös Loránd University, Pázmány Péter sétány $1 / \mathrm{C}$, Budapest, 1117 Hungary

7 Medical University of Vienna, Vienna, Austria

${ }^{8}$ University of Vienna, Vienna, Austria

\section{Abstract}

A growing body of evidence highlights the relationship between epigenetics, especially DNA methylation, and population divergence as well as speciation. However, little is known about how general the phenomenon of epigenetics-wise separation of different populations is, or whether population assignment is, possible based on solely epigenetic marks. In the present study, we compared DNA methylation profiles between four different canine populations: three domestic dog breeds and their ancestor the gray wolf. Altogether, 79 $\mathrm{CpG}$ sites constituting the 65 so-called $\mathrm{CpG}$ units located in the promoter regions of genes affecting behavioral and temperamental traits (COMT, HTR1A, MAOA, OXTR, SLC6A4, TPH1, WFS1) -regions putatively targeted during domestication and breed selection. Methylation status of buccal cells was assessed using EpiTYPER technology. Significant inter-population methylation 
differences were found in $52.3 \%$ of all $\mathrm{CpG}$ units investigated. DNA methylation profile-based hierarchical cluster analysis indicated an unambiguous segregation of wolf from domestic dog. In addition, one of the three dog breeds (Golden Retriever) investigated also formed a separate, autonomous group. The findings support that population segregation is interrelated with shifts in DNA methylation patterns, at least in putative selection target regions, and also imply that epigenetic profiles could provide a sufficient basis for population assignment of individuals.

AQ1

\section{Keywords}

DNA methylation

Canine

Population assignment

Domestication

Behavior

Promoter

Communicated by S. Hohmann.

Electronic supplementary material

The online version of this article (doi: 10.1007/s00438-017-1305-5 ) contains supplementary material, which is available to authorized users.

\section{Introduction}

Epigenetic factors represent a dynamic connection between heritage and environment, making them an ideal prime target for evolutionary processes. Epigenetic states can be highly sensitive to environmental effects (Dolinoy 2008; Turner 2009; Feil and Fraga 2011), but can also be reliably transmitted across generations (Xing et al. 2007; Daxinger and Whitelaw 2010; Gaydos et al. 2014; Bale 2015). It has been theorized that speciation itself begins with variation in epigenetic patterns, followed only later by divergence in DNA sequence (Skinner et al. 2015; Smith et al. 2016). Epigenetic alterations can ultimately induce changes in nucleotide order (Molaro et al. 2011), while on the 
other hand small-scale polymorphisms apparently contribute to modifications in epigenetic marks and, consequently, transcriptional regulation (Fukuda et al. 2013).

Genome-wide DNA methylation data both on closely related species (human and ape) (Mendizabal et al. 2016) and on wild and domesticated strains of the same species (chicken) (Natt et al. 2012) imply that separate populations might show well distinct epigenetic patterns, at least in selective sweep regions. Besides, evidence indicates that such population-specific DNA methylation differences are already present in the germline (Molaro et al. 2011) and that germline DNA methylation states strongly correspond to the somatic ones (Martin et al. 2011), suggesting that inherited epigenetic profiles both constrain the somatic epigenetic landscape and also distinguish closely related species and strains. However, inter-population DNA methylation comparison studies so far have mainly been conducted on a very limited number of subjects, raising the questions whether the observed differences are generally characteristic to entire populations, and if DNA methylation data could solely be sufficient for successful population assignment of individuals.

As implicated by former inter-population DNA methylation studies, population-characteristic differences can principally be expected to be observed in regions under strong selection pressure, be that natural or artificial. Genes affecting temperamental and cognitive traits apparently always constitute a considerable proportion of such genomic loci (Molaro et al. 2011; Natt et al. 2012; Mendizabal et al. 2016), which is probably expected given that adequate adaptation to any novel environmental challenges generally requires alterations in behavioral functions as well. In fact, behavioral isolation itself is considered as a major driver of population divergence and speciation (Verzijden et al. 2012; Sommer-Trembo et al. 2016).

Domestication and breeding process offers an unrivaled opportunity to investigate selection-induced molecular biological changes, including putative shift in epigenetic patterns (Jensen 2015), and of all domesticated species, it is possibly the dog whose investigation is most intriguing. Artificial selection has created a spectacular morphological 
and behavioral diversity in the dog (Careau et al. 2010; McGreevy et al. 2013 ), which has been turned from its large predator ancestor into a popular pet serving man by a variety of ways, and in modern times often sleeping not only in his house but right in his bed. Yet dog and wolf are up today of the same species according to the biological species definition (group of organisms consisting of individuals capable of reproducing fertile offspring). Modern breeding practices have also established multiple closed reproductive populations called breeds, all of which have been selected for a specific desired phenotype-personality traits included (Parker 2012; Wayne and vonHoldt 2012).

In the present study, we compare buccal DNA methylation profiles between promoter regions of behavior-related genes in the gray wolf and three domestic dog breeds selected for characteristically different personality traits: Border Collie, Golden Retriever, and Siberian Husky. Protein products of the investigated genes play part in diverse biochemical pathways and neurotransmission systems (including different monoaminergic and the oxytocin systems as well as endoplasmic reticulum stress signaling) as enzymes, receptors, or transporters. All genes analyzed have variants confirmedly influencing temperament and/or cognitive functions (Shih et al. 1999;

Weinshilboum et al. 1999; Gainetdinov and Caron 2003; Nakamura et al. 2006; Lesch 2007; Kato et al. 2008; Neumann 2008; Ptacek et al. 2011 ), rendering them ideal selection target candidates during domestication and breeding processes.

\section{Materials and methods}

\section{Animals studied}

DNA methylation analysis was carried out on three dog breeds (Golden Retriever, Siberian Husky, and Border Collie) as well as North American timber wolves. All four populations contained 8 individual animals each. Only male animals were investigated. Mean age \pm SD was $3.4 \pm 2.4,4.5 \pm 2.8,3.8 \pm 2.1$, and $4.0 \pm 1.8$ years for Golden Retriever, Siberian Husky, Border Collie, and wolf, respectively. Differences in mean and variance of age were identified as non-significant by one-way ANOVA and Bartlett's test for equal variances $(p=0.8041$ and $p=$ 
0.6735, respectively). All owners volunteered to participate and gave consent to the genetic analysis of their animals and the use of results for research purposes. Dogs were kept as pets; wolves were a zoo-based population living in packs and in regular physical contact with humans at the Wolf Science Center (WSC), Ernstbrunn, Austria. All wolves were born in captivity, hand-raised at the WSC (from age 10 days to about 5 months) and motivation-based clicker trained as adults. More information on wolf-keeping conditions and dog-wolf comparative ethological research at the WSC can be found on http://www.wolfscience.at . Two of the wolves were cousins, otherwise none of them were closely related. Wolves lived in four physically separated packs. Three of them were alpha wolves. None of the dogs of the same breed were closely related (first- and second-degree relatives were automatically excluded). All Golden Retrievers and all Border Collies lived at different households. Of Siberian Huskies, two animals shared a household in three cases. This study required no special permission of the University Institutional Animal Care and Use Committee (IACUC) as non-invasive animal studies are not regarded as animal experiments by the operative law of Hungary (Act XXVIII of 1998 on the protection and welfare of animals).

\section{Sample collection}

Buccal samples were collected from the inner cheek using sterile cotton-tipped swabs. DNA was obtained by a traditional, salting-out procedure (Boor et al. 2002). Briefly, following overnight incubation at $56{ }^{\circ} \mathrm{C}$ in $450 \mu \mathrm{l}$ cell lysis buffer $(0.2 \mathrm{~g} / 1$ Proteinase $\mathrm{K}, 0.1 \mathrm{M} \mathrm{NaCl}, 0.5 \%$ SDS, $0.01 \mathrm{M}$ Tris buffer, $\mathrm{pH}$ 8.0), samples were RNase treated at room temperature and protein precipitated with saturated $(6 \mathrm{M}) \mathrm{NaCl}$. After isopropanol precipitation and ethanol purification, pellets were resuspended in $30 \mu \mathrm{l}$ standard Tris-EDTA solution (0.01 M Tris, 4 $0.001 \mathrm{M}$ EDTA, pH 8.0). DNA was kept at $-20{ }^{\circ} \mathrm{C}$ until bisulfite conversion.

\section{Target region selection}

Genes of interest were those with a proven influence on neurobiological processes and behavior in mammals. Only $\mathrm{CpG}$ island shores in promoter regions were included (up to $2600 \mathrm{bp}$ upstream from 
annotated transcription start site). For gene annotation purposes, genome assembly CanFam3.1 was used (Aken et al. 2016).

Prerequisites for target gene selection included (1) canine promoter sequences available in public databases and (2) confirmed relationship between polymorphisms (preferably regulatory region polymorphisms) and behavioral differences in mammals and, if possible, also in dogs. Care was taken that genes affecting distinct signaling pathways and encoding different types of proteins (e.g., with receptor, transporter, or enzymatic activity) were included. The final gene set was randomly selected from a larger set meeting all the selection criteria.

Localization of $\mathrm{CpG}$ islands was determined using an in-house MSDOS application based on the $\mathrm{CpG}$ island definition of a region of $\geq 200$ bp length with a $>50 \%$ GC percentage and a $>60 \%$ observed-toexpected (O/E) CpG ratio. Short amplicons covering the highest possible number of $\mathrm{CpGs}$ within promoter $\mathrm{CpG}$ island shores were preferred. Sequence match of selected amplicons between domestic dog and wolf (as well as golden jackal) was principally checked using a private database (Department of Ecology and Evolutionary Biology, University of California, LA) with the kind permission of Robert K. Wayne. Existence of polymorphisms was also checked in Ensembl, dbSNP, and DoGSD public databases (Sherry et al. 2001; Bai et al. 2015; Aken et al. 2017). Amplicons containing a possibly polymorphic CpG site were excluded from the study.

On the basis of the above considerations, 12 amplicons in 7 genes of interest were selected. Six of those (COMT, HTR1A, MAOA, OXTR, $S L C 6 A 4$, and TPH1) encode proteins important in neurosignaling, while WFS1 encodes an endoplasmic reticulum transmembrane protein. Level of sequence conservation between all canine sequences investigated was at least $98 \%$ for the target regions.

\section{DNA methylation analysis}

1000 ng genomic DNA quantified by a NanoDrop ND-1000

Spectrophotometer (Thermo Scientific, Wilmington, DE) was bisulfite converted using the EZ DNA Methylation-Gold ${ }^{\mathrm{TM}}$ Kit (Zymo Research, Irvine, CA) according to the manufacturer's protocol. PCR primers were designed by the EpiDesigner online tool 
( http://www.epidesigner.com ). Primer adherence sites are indicated in Supplementary Table 1. Reaction mixture for PCR contained 0.5 units EpiMark Hot Start Taq DNA Polymerase (New England Biolabs, Ipswich, MA), $1 \times$ EpiMark Hot Start Taq Reaction Buffer, $0.2 \mathrm{mM}$ dNTP, $0.2-0.2 \mu \mathrm{M}$ of forward and reverse primers, and about $15-20 \mathrm{ng}$ bisulfite-converted DNA template. Amplification was carried out using 45 cycles. Denaturation step took place at $95{ }^{\circ} \mathrm{C} / 30 \mathrm{~s}$ and elongation at $68^{\circ} \mathrm{C} / 45$ s. For annealing times and temperatures, see Supplementary Table 1. After PCR fragment quality check by gel electrophoresis, amplicons were sent to Agena Bioscience GmbH (Hamburg, Germany) for in vitro RNA transcription by T7 Polymerase, base-specific RNA cleavage and mass spectrometry-based DNA methylation analysis (Ehrich et al. 2005) using MassARRAY ${ }^{\circledR}$ EpiTYPER $^{\circledR}$ technology (Agena Bioscience, San Diego, CA).

For array validation, percent methylation of a CpG site (OXTR_17_3) showing significant inter-population methylation differences was assessed also by pyrosequencing. Primer sequences were as follows: $5^{\prime}$ AGG GTG ATG AAG TTG TAA AAG T 3' (forward), 5' ACA TTT CAT CTT CCT TTA ACA TCA TAT A 3' (reverse), and 5' GGT TTT TTT TTT TTT TGG TTT AGA A 3' (sequencing). Reverse primer was biotinylated on the $5^{\prime}$ end. PCR reaction mixture composition was the same as used at amplification for MassARRAY ${ }^{\circledR}$ EpiTYPER $^{\circledR}$ analysis. Cycling conditions were as follows: Step 1: $\left(95^{\circ} \mathrm{C} / 1 \mathrm{~min}\right) / 1$ cycle; Step 2: $\left(95^{\circ} \mathrm{C} / 30 \mathrm{~s}, 58^{\circ} \mathrm{C} / 1 \mathrm{~min}, 68^{\circ} \mathrm{C} / 45 \mathrm{~s}\right) / 45$ cycles; Step 3: $\left(68^{\circ}\right.$ $\mathrm{C} / 5 \mathrm{~min}) / 1$ cycle; Step $4: 8{ }^{\circ} \mathrm{C}$ hold. Pyrosequencing was performed in triplicate on a PyroMark Q24 platform using PyroMark Gold Q24 Reagents (Qiagen NV, Venlo, NL).

\section{In silico analyses}

Heat map of methylation level per $\mathrm{CpG}$ unit was plotted using MultiExperiment Viewer (MeV) version 4.9.0 ( http://www.tm4.org ). Statistical calculations were performed by GraphPad Prism 5.03 for Windows (GraphPad Software, San Diego, California; http://www.graphpad.com ). One-way ANOVA followed by Tukey -Kramer post hoc test was used for assessing differences in percent methylation between populations. Hierarchical clustering dendrograms 
were obtained by XLSTAT 2015.1 ( http://www.xlstat.com ) applying Ward's method of minimum variance (with Euclidean distance matrix).

\section{Results}

\section{Data quality and study design}

Altogether, $93 \mathrm{CpG}$ sites were covered by the amplicons, 79 of which were analyzable by the MassARRAY ${ }^{\circledR}$ technology. These comprised the 65 so-called $\mathrm{CpG}$ units, which are the smallest possible cleaved fragments analyzed by MassARRAY ${ }^{\circledR}$ assay. Where a CpG unit contained several individual $\mathrm{CpG}$ sites (in 10 cases a $\mathrm{CpG}$ unit included $2 \mathrm{CpG}$ sites, and in 2 cases 3 sites), the average methylation values were reported. Call rate regarding the 65 analyzable $\mathrm{CpG}$ units was 98.3\%. Amplicon sizes, locations, and the number of $\mathrm{CpG}$ units covered are indicated in Table 1 .

AQ2

Table 1

Details of amplicons included in this study

\begin{tabular}{|c|c|c|c|c|}
\hline \multirow{2}{*}{$\begin{array}{l}\text { Amplicon } \\
\text { ID }\end{array}$} & \multirow{2}{*}{$\begin{array}{l}\text { Length } \\
\text { (bp) }\end{array}$} & \multirow{2}{*}{$\begin{array}{l}\text { No. of } \\
\text { CpGs }\end{array}$} & \multicolumn{2}{|l|}{ Location $^{b}$} \\
\hline & & & $\begin{array}{l}\text { Genomic } \\
\text { coordinates }\end{array}$ & $\begin{array}{l}\text { Relative to } \\
\text { TSS }\end{array}$ \\
\hline COMT_17 & 254 & 8 & $\begin{array}{l}26: 29366089 \\
-29366342\end{array}$ & -335 to -82 \\
\hline COMT_26 & 194 & 6 & $\begin{array}{l}26: 29366881 \\
-29367074\end{array}$ & $\begin{array}{l}-1068 \text { to } \\
-874\end{array}$ \\
\hline HTR1A_14 & 204 & 4 & $\begin{array}{l}2: 50007473 \\
-50007676\end{array}$ & $\begin{array}{l}-1127 \text { to } \\
-924\end{array}$ \\
\hline MAOA_17 & 199 & 4 & $\begin{array}{l}X: 37676796 \\
-37676994\end{array}$ & $\begin{array}{l}-696 \text { to } \\
-498\end{array}$ \\
\hline MAOA_22 & 205 & 13 & $\begin{array}{l}X: 37677110 \\
-37677314\end{array}$ & $\begin{array}{l}-382 \text { to } \\
-178\end{array}$ \\
\hline \multicolumn{5}{|c|}{$T S S$ transcription start site } \\
\hline \multicolumn{5}{|c|}{$\begin{array}{l}{ }^{\mathrm{a} O n l y} \text { numbers of CpGs analyzable by MassARRAY }{ }^{\circledR} \text { EpiTYPER }^{\circledR} \\
\text { technology are indicated }\end{array}$} \\
\hline \multicolumn{5}{|c|}{${ }^{\mathrm{b}}$ According to Ensembl annotation CanFam3.1 (GCA_000002285.2) } \\
\hline
\end{tabular}

http://eproofing.springer.com/journals/printpage.php?token=9TJDw81DY5-Mtt0ArK... 2017.03.20. 


\begin{tabular}{|c|c|c|c|c|}
\hline \multirow{2}{*}{$\begin{array}{l}\text { Amplicon } \\
\text { ID }\end{array}$} & \multirow{2}{*}{$\begin{array}{l}\text { Length } \\
\text { (bp) }\end{array}$} & \multirow{2}{*}{$\begin{array}{l}\text { No. of } \\
\text { CpGs }\end{array}$} & \multicolumn{2}{|l|}{ Location $^{b}$} \\
\hline & & & $\begin{array}{l}\text { Genomic } \\
\text { coordinates }\end{array}$ & $\begin{array}{l}\text { Relative to } \\
\text { TSS }\end{array}$ \\
\hline OXTR_17 & 246 & 6 & $\begin{array}{l}20: 9358073 \\
-9358318\end{array}$ & $\begin{array}{l}-124 \text { to } \\
+122\end{array}$ \\
\hline OXTR_34 & 148 & 4 & $\begin{array}{l}20: 9357391 \\
-9357538\end{array}$ & $\begin{array}{l}-805 \text { to } \\
-658\end{array}$ \\
\hline SLC6A4_8 & 164 & 4 & $\begin{array}{l}9: 44261258 \\
-44261421\end{array}$ & $\begin{array}{l}-1706 \text { to } \\
-1543\end{array}$ \\
\hline TPH1_2 & 470 & 4 & $\begin{array}{l}21: 40573179 \\
-40573648\end{array}$ & $\begin{array}{l}-2026 \text { to } \\
-1555\end{array}$ \\
\hline TPH1_7 & 359 & 5 & $\begin{array}{l}21: 40571913 \\
-40572247\end{array}$ & $\begin{array}{l}-624 \text { to } \\
-266\end{array}$ \\
\hline WFS1_15 & 289 & 15 & $\begin{array}{l}13: 38468824 \\
-38469111\end{array}$ & $\begin{array}{l}-1992 \text { to } \\
-1703\end{array}$ \\
\hline WFS1_32 & 198 & 7 & $\begin{array}{l}13: 38469484 \\
-38469681\end{array}$ & $\begin{array}{l}-2562 \text { to } \\
-2365\end{array}$ \\
\hline \multicolumn{5}{|c|}{$T S S$ transcription start site } \\
\hline \multicolumn{5}{|c|}{$\begin{array}{l}{ }^{a} \text { Only numbers of CpGs analyzable by MassARRAY }{ }^{\circledR} \text { EpiTYPER }^{\circledR} \\
\text { technology are indicated }\end{array}$} \\
\hline \multicolumn{5}{|c|}{ becording to Ensembl annotation CanFam3.1 (GCA_000002285.2) } \\
\hline
\end{tabular}

A CpG site (OXTR_17_CpG_3) with wide methylation range (18-52\%) showing also significant inter-population methylation differences was selected for validation by pyrosequencing. Methylation levels measured by MassARRAY ${ }^{\circledR}$ significantly correlated with the results obtained from pyrosequencing $(r=0.95, p<0.0001)$.

\section{Characteristics and descriptive statistics of CpG units analyzed}

Methylation levels and ranges largely varied with $\mathrm{CpG}$ unit (Fig. 1 ). $24.6 \%$ (16 of 65 ) of all $\mathrm{CpG}$ units analyzed showed minimal, i.e., $\leq 5 \%$, variation in methylation, while $44.6 \%$ (29 of 65) proved to be highly ( $\geq 20 \%$ ) variable (Fig. 2 a). Minimum observed variation in methylation levels was $1 \%$, and the maximum was $68 \%$. CpG units with $\leq 5 \%$ variation in methylation fell in extreme methylation ranges (either $>90$ or $<5 \%$ ) with only a single exception, which actually consisted of 3 
Inpkirisdteas (WFS1_32_CpG_6.7.8; methylation range 76 $-80 \%)$.

Fig. 1

Heat map showing the methylation ratios for each combination of samples and $\mathrm{CpG}$ units. $\mathrm{CpG}$ units are arranged along the $x$-axis and samples are arranged along the $y$-axis. COMT catechol-omethyltransferase, HTR1A 5-hydroxytryptamine receptor 1A, MAOA monoamine oxidase A, OXTR oxytocin receptor, SLC6A4 solute carrier family 6 member 4, TPH1 tryptophan hydroxylase 1, WFS1 wolframin endoplasmic reticulum transmembrane glycoprotein. $G$ Golden Retriever, $H$ Siberian Husky, $B$ Border Collie, $W$ wolf. Color code indicates percent methylation, ranging from $0.0 \%$ (light green) through $0.5 \%$ (black) to $1.0 \%$ (light red). Gray color indicates missing data values

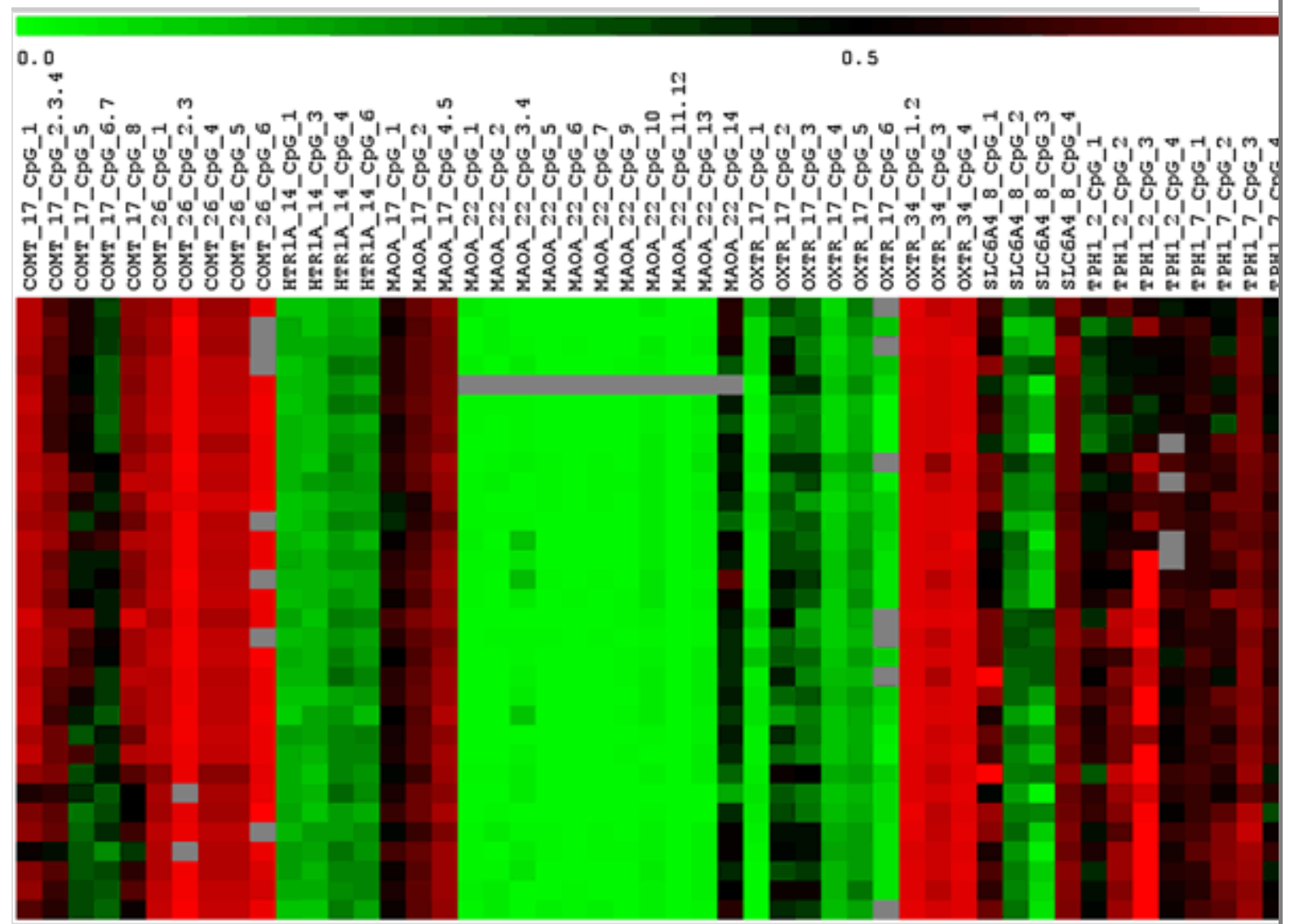

Fig. 2

Characteristics of the $\mathrm{CpG}$ units analyzed. $\mathrm{CpG}$ units comprising a single or several (2 or 3 ) individual $\mathrm{CpG}$ sites are indicated separately. a 
Distribution of the number of $\mathrm{CpG}$ units of a given variance range. $\mathbf{b}$ Difference between methylation variability* of neighboring $\mathrm{CpG}$ units. *Difference between methylation variability was measured by the formula: $\left|\left(H_{A}-L_{A}\right)-\left(H_{B}-L_{B}\right)\right|\left(H_{A}\right.$ being the highest methylation value detected for $\mathrm{CpG}$ unit $\mathrm{A}, L_{A}$ the lowest methylation value detected for $\mathrm{CpG}$ unit $\mathrm{A}, H_{B}$ the highest methylation value detected for $\mathrm{CpG}$ unit $\mathrm{B}$, and $L_{B}$ the lowest methylation value detected for $\mathrm{CpG}$ unit B)



Neighboring CpG units generally showed overlapping or nearly overlapping methylation ranges, with a $\leq 5 \%$ difference between the highest detected methylation value for one $\mathrm{CpG}$ site and the lowest detected methylation value for its neighbor. Considering $\mathrm{CpG}$ units comprising a single $\mathrm{CpG}$ site only, those not fitting in these categories (e.g., those with non-overlapping methylation ranges where the difference between the highest detected methylation value for one $\mathrm{CpG}$ site and the lowest detected methylation value for its neighbor was $>5 \%)$ were observed in the case of only two out of $34(5.9 \%) \mathrm{CpG}$ neighbor pairs altogether. 
Difference in methylation variability was also generally low between neighboring $\mathrm{CpG}$ units, or, in other words, $\mathrm{CpG}$ units with a relatively wide methylation range were likely to have at least one neighboring CpG unit with wide methylation range as well, and vice versa (Fig. 2b). Using the formula $\left|\left(H_{A}-L_{A}\right)-\left(H_{B}-L_{B}\right)\right|$ for expressing the difference between methylation variability (where $H_{A}$ and $L_{A}$ stand for the highest and lowest percentage methylation values observed for $\mathrm{CpG}$ unit A and accordingly, $H_{B}$ and $L_{B}$ stand for the highest and lowest percentage methylation values observed for the neighboring $\mathrm{CpG}$ unit B), a $\leq 5 \%$ difference was observed in the case of 20 of all $56(35.7 \%)$ CpG unit neighbor pairs, and altogether 32 (57.1\%) CpG unit neighbor pairs showed a $\leq 10 \%$ difference. Considering $\mathrm{CpG}$ unit pairs where both $\mathrm{CpG}$ units comprised a single $\mathrm{CpG}$ site only, this phenomenon was even more pronounced: 20 of all 36 (55.5\%) such CpG site pairs showed a $\leq 5 \%$ difference in methylation variability.

\section{Differences in average amplicon methylation between populations}

Average methylation values per amplicon were compared between the gray wolf and three purebred dog breeds: Golden Retriever, Siberian Husky, and Border Collie (Supplementary Table 2). Statistically significant $(p<0.05)$ inter-population differences were obtained in five of the 12 amplicons analyzed. Four of these, located in COMT, TPH1, and WFS1 promoter regions, reached the level of significance of $p<$ 0.0001 . Wolf characteristic methylation values always score in the extreme range (either lowest or highest) (Supplementary Fig. 1).

\section{CpG units with significant inter-population methylation differences}

In order to gain a more detailed insight into population-specific methylation patterns, methylation statuses of each single $\mathrm{CpG}$ unit were also compared between the four populations. Tukey's test following one-way ANOVA showed significant differences between at least two canine populations in 52.3\% (34 of altogether 65) of $\mathrm{CpG}$ units analyzed (Table 2). Wolves presented with the highest number of significant pair-wise differences (58 vs. 50, 45, and 37 in Golden 
Retrievers, Siberian Huskies, and Border Collies, respectively).

Similarly, the highest number of extremely significant $(p<0.0001)$ pairwise $\mathrm{CpG}$ unit methylation differences was also obtained in the case of wolves (41 vs. 25, 24, and 20 in Golden Retrievers, Siberian Huskies, and Border Collies, respectively).

\section{Table 2}

$\mathrm{CpG}$ units with significant pair-wise inter-population methylation differences acc hoc test following one-way ANOVA

\begin{tabular}{|c|c|c|c|c|c|c|}
\hline \multicolumn{2}{|l|}{ Region } & \multirow[b]{2}{*}{$\begin{array}{l}\text { ANOVA } \\
p\end{array}$} & \multicolumn{4}{|c|}{ Inter-group difference significant by Tukey' } \\
\hline Amplicon & CpG & & $\begin{array}{l}\text { Golden } \\
\text { Retriever } \\
\text { vs. } \\
\text { Siberian } \\
\text { Husky }\end{array}$ & $\begin{array}{l}\text { Golden } \\
\text { Retriever } \\
\text { vs. } \\
\text { Border } \\
\text { Collie }\end{array}$ & $\begin{array}{l}\text { Golden } \\
\text { Retriever } \\
\text { vs. Wolf }\end{array}$ & $\begin{array}{l}\text { Siberian } \\
\text { Husky } \\
\text { vs. } \\
\text { Border } \\
\text { Collie }\end{array}$ \\
\hline \multirow{5}{*}{$\mathrm{COMT}_{-} 17$} & 1 & $<0.0001$ & No & No & Yes*** & No \\
\hline & $\begin{array}{l}2-3 \\
-4\end{array}$ & 0.0003 & Yes** & No & No & No \\
\hline & 5 & $<0.0001$ & No & No & Yes*** & No \\
\hline & $6-7$ & $<0.0001$ & Yes*** & Yes* & No & No \\
\hline & 8 & $<0.0001$ & No & No & Yes*** & No \\
\hline MAOA_17 & $4-5$ & 0.0274 & No & Yes* & No & No \\
\hline \multirow{7}{*}{ MAOA_22 } & 1 & 0.0204 & No & Yes* & No & Yes* \\
\hline & 2 & 0.0050 & No & No & No & No \\
\hline & 5 & 0.0163 & Yes* & No & No & No \\
\hline & 7 & 0.0163 & Yes* & No & No & No \\
\hline & 9 & 0.0158 & No & No & No & No \\
\hline & 10 & 0.0372 & No & No & No & No \\
\hline & $\begin{array}{l}11 \\
-12\end{array}$ & $<0.0001$ & Yes*** & No & No & Yes*** \\
\hline OXTR_17 & 3 & 0.0010 & No & No & Yes** & No \\
\hline
\end{tabular}




\begin{tabular}{|c|c|c|c|c|c|c|}
\hline \multicolumn{2}{|l|}{ Region } & \multirow[b]{2}{*}{$\begin{array}{l}\text { ANOVA } \\
p\end{array}$} & \multicolumn{4}{|c|}{ Inter-group difference significant by Tukey } \\
\hline \multirow[t]{2}{*}{ Amplicon } & CpG & & $\begin{array}{l}\text { Golden } \\
\text { Retriever } \\
\text { vs. } \\
\text { Siberian } \\
\text { Husky }\end{array}$ & $\begin{array}{l}\text { Golden } \\
\text { Retriever } \\
\text { vs. } \\
\text { Border } \\
\text { Collie }\end{array}$ & $\begin{array}{l}\text { Golden } \\
\text { Retriever } \\
\text { vs. Wolf }\end{array}$ & $\begin{array}{l}\text { Siberian } \\
\text { Husky } \\
\text { vs. } \\
\text { Border } \\
\text { Collie }\end{array}$ \\
\hline & 4 & $<0.0001$ & No & Yes* & Yes*** & No \\
\hline \multirow[t]{2}{*}{ SLC6A4_8 } & 4 & 0.0156 & No & No & No & Yes* \\
\hline & 1 & 0.0006 & Yes* & Yes*** & Yes* & No \\
\hline \multirow{3}{*}{ TPH1_2 } & 2 & $<0.0001$ & No & Yes*** & Yes*** & Yes*** \\
\hline & 3 & 0.0014 & Yes*** & Yes*** & Yes*** & No \\
\hline & 4 & 0.0002 & Yes*** & No & No & Yes*** \\
\hline \multirow{5}{*}{ TPH1_7 } & 1 & 0.0053 & No & Yes* & Yes* & No \\
\hline & 2 & 0.0016 & Yes* & No & Yes** & No \\
\hline & 3 & $<0.0001$ & No & No & Yes*** & Yes* \\
\hline & 4 & $<0.0001$ & Yes*** & Yes*** & No & No \\
\hline & 5 & 0.0038 & No & No & Yes** & No \\
\hline \multirow{8}{*}{ WFS1_15 } & 10 & $<0.0001$ & Yes** & Yes** & Yes*** & No \\
\hline & 11 & $<0.0001$ & Yes** & Yes*** & Yes*** & Yes*** \\
\hline & $\begin{array}{l}12 \\
-13\end{array}$ & $<0.0001$ & No & No & Yes*** & No \\
\hline & 14 & $<0.0001$ & Yes** & Yes* & Yes*** & No \\
\hline & $\begin{array}{l}15 \\
-16\end{array}$ & $<0.0001$ & No & No & Yes*** & No \\
\hline & 17 & $<0.0001$ & Yes* & Yes* & Yes*** & No \\
\hline & 18 & $<0.0001$ & Yes** & No & Yes*** & No \\
\hline & $\begin{array}{l}19 \\
-20\end{array}$ & $<0.0001$ & No & Yes** & Yes*** & No \\
\hline WFS1_32 & 2 & 0.0319 & No & Yes* & No & No \\
\hline
\end{tabular}

Each row represents a $\mathrm{CpG}$ unit (consisting of 1-3 individual $\mathrm{CpG}$ sites). Level pair-wise difference in methylation is indicated by the number of asterisks (sigr $0.05)$ : single asterisk; very significant $(0.001 \leq p<0.01)$ : two asterisks; highly s $0.001)$ : three asterisks) 
The vast majority $(82.3 \% ; 28$ of 34$)$ of $\mathrm{CpG}$ units showing significant $(p<0.05)$ pair-wise methylation differences between at least two populations emerged in $\mathrm{CpG}$ units with high, $\geq 20 \%$ variation in methylation levels. On the reverse, significant inter-population differences were found in $72.4 \%$ ( 21 of 29 ) of all $\mathrm{CpG}$ units with $\geq 20 \%$ variation in methylation. Considering $\mathrm{CpG}$ units with highly significant $(p<0.001)$ pair-wise methylation differences only, 90.9\% (20 of altogether 22 ) of those showed $\geq 20 \%$ variation in methylation, and highly significant inter-population differences were observed in $65.5 \%$ (19 of 29) of all CpG units with $\geq 20 \%$ variation in methylation. Lowest degree of variation in methylation yielding significant pair-wise interpopulation differences was $11 \%$ (in OXTR_17_CpG_4), where the level of significance reached $p<0.001$.

\section{Cluster analysis}

Hierarchical cluster analysis based on Ward's minimum variance between individual animals' methylation profiles (on the $\mathrm{CpG}$ unit level) indicated three distinct groups (Fig. 3). Central objects to groups/classes 1, 2, and 3 were Golden Retriever G3, Siberian Husky H6, and wolf W8, respectively. Distance between central objects of the classes was as follows: 0.736 for groups 1 and 2, 1.045 for groups 1 and 3 , and 0.797 for groups 2 and 3, while the distance between the class centroids was as follows: 0.570 for groups 1 and 2, 0.984 for groups 1 and 3, and 0.671 for groups 2 and 3. Within-class variance regarding groups 1,2 , and 3 was $0.147,0.242$, and 0.214 , respectively. Average distance to centroid by class was 0.351 (range $0.254-0.475$ ), 0.463 (range $0.324-0.790$ ), and 0.413 (range $0.281-0.681$ ) for groups 1, 2, and 3, respectively. Variance decomposition for the optimal classification values was $58.78 \%$ for within-class variation and $41.22 \%$ for the between-class differences.

\section{Fig. 3}

Hierarchical cluster analysis based on $\mathrm{CpG}$ unit level methylation profiles. Euclidean distances of the three classes are shown together with pair-wise dissimilarities in methylation patterns regarding all animals investigated. $W$ wolf, $G$ Golden Retriever, $H$ Siberian Husky, $B$ Border 
Collie, C1/C2/C3: group/class 1/2/3. a Dendrogram for distribution of individual animals. b Dendrogram for classes


Segregation of wolf from domestic dog was unambiguous, as all wolves investigated belonged to a single cluster (group 3) containing no dogs at all and also showing a markedly higher degree of dissimilarity from both of the other two clusters than those from each other. Regarding dogs only, one of the three breeds (Golden Retriever) also formed a separate group (group 1); however, representatives of the two remaining breeds (Siberian Husky and Border Collie) were assigned to the same cluster (group 2).

\section{Discussion}

Here we provide supporting evidence for an altered epigenetic state of genes related to behavioral and cognitive functions between dog and wolf and, to a lesser extent, also between dog breeds. The findings are in harmony with genome-wide DNA methylation data on dog contra wolf (Janowitz Koch et al. 2016) as well as on natural darter 
populations exhibiting different stages of evolutionary divergence (Smith et al. 2016), wild and domesticated chicken strains, and also human versus ape (Mendizabal et al. 2016). Yet, to our best knowledge, this is the first time when DNA methylation status has been demonstrated to provide a suitable basis for population assignment of individuals even with a relatively few and moderately variable markers, at least when promoter regions of a probable selection target gene group are interrogated.

Naturally, comprehensive interpretation of the findings would require further, extensive investigations. Perhaps most importantly, functional relevance of $\mathrm{CpG}$ sites showing population-specific differential methylation should be elucidated. Theoretically, promoter methylation levels of behavior-related genes could exert considerable influence on temperament and cognition, and thus the observed DNA methylation differences could contribute to the characteristic behavioral differences between the study populations. Methylation levels of promoter regions have often been shown to strongly correlate with gene expression levels (Portela and Esteller 2010). Also, characteristic, and apparently hereditary, gene expressional differences have been described in the brain of wild versus domesticated or tame strains of several species, including dog and wolf (Kukekova et al. 2011; Albert et al. 2012; Li et al. 2013), just as in aggressive contra non-aggressive dogs (Vage et al. 2010). Besides, DNA methylation together with other types of epigenetic modifications is a confirmed regulator of emotional behavior, behavioral memory, and synapse plasticity (Miller and Sweatt 2007; Miller et al. 2008, 2010; LaPlant et al. 2010; Yu et al. 2011).

However, presently it is uncertain whether methylation states of the here analyzed regions, especially as measured in buccal epithelial tissue, indeed correspond to gene expression and functioning. Epigenetic regulation is tissue specific, and hence behavior can only be influenced by DNA methylation patterns of the brain. Yet, some data point that methylation states, both global and $\mathrm{CpG}$-wise, of a peripheral surrogate tissue often reflect effectively on that of the brain (Gregory et al. 2009; Thompson et al. 2013; Walton et al. 2016). Surprisingly, this can apply even when significant inter-tissue differences in RNA expression are present (Horvath et al. 2012). Human-related studies 
found dynamic changes in promoter methylation of stress-related genes, including the here analyzed $O X T R$, in white blood cells upon acute psychosocial stress (Unternaehrer et al. 2012), regardless of the fact that methylation of the human OXTR promoter had earlier been found to regulate gene expression in a tissue-specific manner (Kusui et al. 2001) and that $O X T R$ expression in blood is negligible in comparison to brain according to the AceView annotation

( http://www.ncbi.nlm.nih.gov/IEB/Research/Acembly ) (Thierry-Mieg and Thierry-Mieg 2006). Methylation states of OXTR promoter as measured in peripheral blood cells have been shown to associate with childhood maternal care (Unternaehrer et al. 2015), and OXTR promoter methylation levels in saliva correlated with anxiety/ depression (Chagnon et al. 2015). OXTR promoter methylation in blood has been found to closely correspond to neural response to ambiguous social stimuli in several brain regions according to functional magnetic resonance image (fMRI) scanning (Jack et al. 2012) as well. Although the other genes involved in this study are yet underinvestigated with regard to DNA methylation, especially in canines, studies on human OXTR indicate that data gained from surrogate tissues might be more valuable also from the functional aspect, than it could be assumed based on purely theoretical considerations.

Of the most commonly used peripheral tissues, buccal epithelial tissue seems to be an even better option than blood (Lowe et al. 2015; Smith et al. 2015 ) at least partly because of the unique methylation profile of the latter (Varley et al. 2013; Lokk et al. 2014). The fact that buccal epithelial cells are of the same embryologic ectodermic origin as neurons (Solnica-Krezel and Sepich 2012) provides a plausible biological ground as to why buccal methylation patterns could reliably reflect on that of the nervous system, especially if these patterns are already present at an early stage of embryonic development, just as it can be expected with inherited epigenetic marks. Presumably, in the course of tissue differentiation, cells and tissues derived from the same germ layer develop their own epigenetic patterns at varying rates and extents, so that in the adult organism high levels of inter-tissue DNA methylation correlation might be found where divergence rates were either low or where basically similar changes occurred. Indeed, it has been shown that DNA methylation levels can highly vary between 
different brain areas (Harony-Nicolas et al. 2014; Hannon et al. 2015) and even between neuronal subtypes (Kozlenkov et al. 2016). Importantly, however, DNA methylation patterns were shown to be generally more homogeneous between different brain regions of the same individual than they are for the same brain region from different individuals (Illingworth et al. 2015). It is thus reasonable to assume a similar scenario for another ectoderm-derived tissue, justifying the usefulness of buccal epithelia for exploring population-specific methylation patterns. Nevertheless, it must be emphasized that only an exceedingly comprehensive, cell type-level inter-tissue DNA methylation analysis could provide a full picture, ideally with the inclusion of possible brain regions at all developmental stages and on a suitably large sample size to allow for statistical correction of multiple comparisons. Still, it might as well be that the nature of the observed relationship between buccal methylation states and population assignment lies somewhere else than brain expression levels. However, it seems unlikely that any epigenetic mark could show unambiguously population-specific patterns if it has no genuine biological relevance on gene expression levels.

Exploring the regulatory potential of the regions showing significant inter-population methylation differences would also be crucial. Unfortunately, experimental and observational data on the role of (putative) canine gene regulatory regions at present are extremely scarce. Of the here investigated genes, such information is only available with respect to $M A O A$ (Eo et al. 2016). In this recent work, brain DNA methylation levels were investigated in three $M A O A$ promoter segments together with mRNA expression levels in different breed dogs. Notably, one of the three promoter segments ("Region 1") overlapped precisely with the here analyzed amplicon MAOA_22. Similarly to our findings, marked differences were found between DNA methylation levels of the three breeds investigated, and there was a strong negative correlation between DNA methylation and gene expression levels. Indirect evidence also strongly supports the gene expression regulatory effect of MAOA_22 as well as of OXTR_17, since human orthologous fragments are indicated to be associated with the binding of several transcription factors and active chromatin marks including histone acetylation and DNAse I hypersensitivity clusters (the 


\section{talceivelsceeth sepesalbbrathe ENCODE}

Consortium database ( https://genome.ucsc.edu/) (Consortium 2012). Besides, human orthologous fragment of OXTR_34 was found to be associated with CTCF binding and DNAse I hypersensitivity clusters, and the direct neighborhood of the human orthologous fragment of HTR1A_14 was associated with transcription factor binding and histone acetylation. However, these data can by no means fully compensate for the lack of data on canines, and not even such an indirect evidence is available on most regions investigated in this study (namely COMT_17, COMT_26, MAOA_17, SLC6A4_8, TPH1_2, TPH1_7, WFS1_15, and WFS1_32) due to the complete lack of inter-species sequence homology at the investigated non-coding regions. Yet, it must be mentioned that online transcription factor binding predictor tools JASPAR (Sandelin et al. 2004; Mathelier et al. 2016) and PROMO (Messeguer et al. 2002; Farre et al. 2003 ) identified several putative transcription factor binding sites in all amplicons analyzed, irrespective of the level of phylogenetic conservation of their sequences. This fits in perfectly with the observation that the methylation status of promoter and nearpromoter $\mathrm{CpG}$ island shores, like the here investigated regions, often influences transcription efficiency of the proximal genes. In silico analyses thus support that the regions investigated might bear regulatory potential, even though this cannot be unambiguously stated in the lack of confirmatory experimental data.

Given the well-known influence of environmental factors on DNA methylation levels (Aguilera et al. 2010; Parle-McDermott and Ozaki 2011; Szyf 2011), the role of heredity versus environment in the observed population segregation is also to be elucidated. At present, it can only be stated that all dogs involved in the study, independent of breed, were family dogs living in different households, and thus environmental differences as causative factors in the segregation of Golden Retriever from the other two dog breeds seem unlikely. With regard to wolves, the situation is slightly complex. Clearly, they were not family pets, but their keeping conditions had many in common with those of dogs and markedly differed from those of free-ranging wild wolves. They were hand-raised, had regular contact with humans also in adulthood, and underwent clicker training similar to dogs. Besides, they constituted a heterogeneous population with regard to social effects, as 
they were members of separate packs and occupied different ranks in the hierarchy. Yet, they formed a uniform cluster in terms of DNA methylation, implying that the role of environment might be minor compared to the role of heredity in their segregation from dog.

Of similar concern is the inclusion of North American timber wolves instead of a Eurasian wolf population. Although the exact location of the domestication center is still disputed (vonHoldt et al. 2010), it is agreed upon that the domestic dog evolved in the Eurasian continent, most possibly in Southeast Asia (Savolainen et al. 2002; Ding et al. 2012; Thalmann et al. 2013). This naturally raises the question whether the observed dog-wolf DNA methylation differences might rather reflect wolf phylogeny than dog domestication and artificial selection. Yet, North American timber wolves might not represent a particularly more remote population from dog than any modern Eurasian wolves. Evidence indicates that the domestic dog derived from a founder population with a fairly larger genetic diversity than observed among any modern wolf populations (Freedman et al. 2014). Besides, the most careful estimations put dog domestication at about 11,000-14,000 years ago (Axelsson et al. 2013; Freedman et al. 2014), with some at about already 33,000 years ago (Germonpre et al. 2009; Wang et al. 2016). North American timber wolves are believed to represent the last of three separate invasions into North America at about 11,000-12,000 years ago from Eastern Asia through the Bering land bridge (Vila et al. 1999), implying that the ancestors of North American timber wolves could have been similarly closely related to those of dogs as ancestors of modern Eurasian wolves themselves.

Another important issue would be to explore whether the findings also apply for non-brain-related genes, non-promoter regions, and epigenetic modifications other than DNA methylation (i.e., histone modifications and non-coding RNA species). Evidence suggests that the answer to at least the first two questions is yes, although the extent of interpopulation DNA methylation differences might considerably vary with gene function and region. A recent study investigating DNA methylation in dog and wolf blood samples using reduced representation bisulfite sequencing (Janowitz Koch et al. 2016) found that domestication-associated differentially methylated CpGs were 
highly enriched for repeat regions and included several functionally relevant gene ontology groups, including, but not restricted to, genes involved in neurobiological processes. Notably, this study also found that dogs and wolves formed different clusters based on methylation data, even though population subdivision varied with the analysis method. Yet, unpublished data of our group on DNA methylation in promoter regions of 20 genes in mixed-breed dogs and wolves living under the same conditions also indicate the existence of dog- and wolfspecific methylation patterns, but at the same time results also hint that this phenomenon is dependent on the gene categories investigated. It must also be noted that although all genes analyzed in the present study were previously shown to affect behavior, not all of them are classical behavior-related genes. Wolframin gene (WFS1) encodes an endoplasmic reticulum transmembrane protein and is expressed bodywide (De Falco et al. 2012), with its highest expression levels being reported in non-brain tissues. Besides, even genes typically associated with neurosignaling including $C O M T$ encoding catechol-O-methyltransferase or $T P H 1$ encoding tryptophan hydroxylase are expressed in several non-brain tissues at levels similar to those observed in the brain, making the picture even more complex. Importantly, comparative brain methylome analysis on chicken domestication (Natt et al. 2012) indicated that inter-population differentially methylated regions are enriched in genes related to cell signaling, thereby influencing stress tolerance, cognitive functions, and reproduction-features that are important from the domestication perspective. It was also shown that epigenetically affected genes were over-represented in selective sweep regions. Yet, a muscle methylome analysis on chicken strains found a large degree of conservation instead of divergence in promoter methylation states (Li et al. 2015), implying that population-specific epigenetic shifts do not occur randomly. In concert with these findings are the results gained from larger evolutionary scale methylome comparison studies between human and ape, with regard to both brain and non-brain tissues (Molaro et al. 2011; Pai et al. 2011; Mendizabal et al. 2016). These studies also highlighted that inter-species differentially methylated regions can be identified at least as frequently in extra-promoter regions (i.e., in gene bodies and intergenic regions) as within promoters (Mendizabal et al. 
2016), similar to tissue-specific differentially methylated regions (Lokk et al. 2014).

The observation that also $\mathrm{CpG}$ sites with modest degrees of methylation variation can show population-specific methylation differences would also require further validation and elucidation. Similarly, extensive investigations would be needed for estimating the occurrence and determining the significance of differentially methylated CpGs located in regions that otherwise show low levels of methylation variability and lack population-specific patterns. General observations highlight that the methylation levels of neighboring $\mathrm{CpG}$ sites tend to fall into overlapping ranges, and genomic regions of marginally high and low levels of methylation are typically separated by an intermittent zone, where the methylation levels of neighboring $\mathrm{CpG}$ sites gradually change (Mikeska et al. 2007; Couldrey and Lee 2010). Our results also demonstrated that the neighboring $\mathrm{CpG}$ sites often relatively show differences in the extent of methylation variability, rendering it challenging to predict on the characteristics of a single $\mathrm{CpG}$ site in the absence of referring experimental and observational data.

In summary, many open questions remain with regard to full interpretation of the results. Yet, despite all the limitations of this study, the perspectives offered by the findings are intriguing. Apparently, epigenetic divergence of populations can be specific to the level making population assignment of individuals as well as phylogeny reconstruction possible purely based on epigenetic marks, at least when regulatory regions of putative selection target genes are interrogated. Apart from the direct practical aspects of these perspectives, the findings also add to the growing body of evidence that epigenetic changes accompany, if not downright drive, population segregation processes.

\section{Acknowledgements}

This study was funded by the National Scientific Fund of Hungary (Grant numbers OTKA ANN 107726 and OTKA K 112138), the Austrian Science Fund (Grant number FWF I 1271-B24), and the Vienna Science and Technology Fund (Grant number WWTF CS11- 
026). Eniko Kubinyi was supported by the Bolyai Foundation. The authors would like to thank Peter Marx for providing help with wolf sequence data collection and analysis.

Compliance with ethical standards

Conflict of interest All the authors declare no conflict of interest.

Ethical approval All applicable international, national, and/or institutional guidelines for the care and use of animals were followed. This article does not contain any studies with human participants performed by any of the authors.

\section{Electronic supplementary material}

Below is the link to the electronic supplementary material.

Supplementary Fig. 1: Percent methylation of amplicons with $p=0.0001$ inter-population differences in the four populations investigated. Methylation values for each individual animal are indicated. Horizontal lines represent mean values \pm SD (standard deviation) (TIF $42932 \mathrm{~KB}$ )

Supplementary Table 1 (DOC 47 KB)

Supplementary Table 2 (DOC 103 KB)

\section{References}

Aguilera O, Fernandez AF, Munoz A, Fraga MF (2010) Epigenetics and environment: a complex relationship. J Appl Physiol (1985) 109:243-251

Aken BL, Ayling S, Barrell D, Clarke L, Curwen V, Fairley S, Fernandez Banet J, Billis K, Garcia Giron C, Hourlier T, Howe K, Kahari A, Kokocinski F, Martin FJ, Murphy DN, Nag R, Ruffier M, 
Schuster M, Tang YA, Vogel JH, White S, Zadissa A, Flicek P, Searle SM (2016) The Ensembl gene annotation system. Database 2016: baw093

Aken BL, Achuthan P, Akanni W, Amode MR, Bernsdorff F, Bhai J, Billis K, Carvalho-Silva D, Cummins C, Clapham P, Gil L, Giron CG, Gordon L, Hourlier T, Hunt SE, Janacek SH, Juettemann T, Keenan S, Laird MR, Lavidas I, Maurel T, McLaren W, Moore B, Murphy DN, Nag R, Newman V, Nuhn M, Ong CK, Parker A, Patricio M, Riat HS, Sheppard D, Sparrow H, Taylor K, Thormann A, Vullo A, Walts B, Wilder SP, Zadissa A, Kostadima M, Martin FJ, Muffato M, Perry E, Ruffier M, Staines DM, Trevanion SJ, Cunningham F, Yates A, Zerbino DR, Flicek P (2017) Ensembl 2017. Nucleic Acids Res 45:D635-D642

Albert FW, Somel M, Carneiro M, Aximu-Petri A, Halbwax M, Thalmann O, Blanco-Aguiar JA, Plyusnina IZ, Trut L, Villafuerte R, Ferrand N, Kaiser S, Jensen P, Paabo S (2012) A comparison of brain gene expression levels in domesticated and wild animals. PLoS Genet 8:e1002962

Axelsson E, Ratnakumar A, Arendt ML, Maqbool K, Webster MT, Perloski M, Liberg O, Arnemo JM, Hedhammar A, Lindblad-Toh K (2013) The genomic signature of dog domestication reveals adaptation to a starch-rich diet. Nature 495:360-364

Bai B, Zhao WM, Tang BX, Wang YQ, Wang L, Zhang Z, Yang HC, Liu YH, Zhu JW, Irwin DM, Wang GD, Zhang YP (2015) DoGSD: the dog and wolf genome SNP database. Nucleic Acids Res 43:D777-D783

Bale TL (2015) Epigenetic and transgenerational reprogramming of brain development. Nat Rev Neurosci 16:332-344

Boor K, Ronai Z, Nemoda Z, Gaszner P, Sasvari-Szekely M, Guttman A, Kalasz H (2002) Noninvasive genotyping of dopamine receptor D4 (DRD4) using nanograms of DNA from substancedependent patients. Curr Med Chem 9:793-797 
Careau V, Reale D, Humphries MM, Thomas DW (2010) The pace of life under artificial selection: personality, energy expenditure, and longevity are correlated in domestic dogs. Am Nat 175:753-758

Chagnon YC, Potvin O, Hudon C, Preville M (2015) DNA methylation and single nucleotide variants in the brain-derived neurotrophic factor (BDNF) and oxytocin receptor (OXTR) genes are associated with anxiety/depression in older women. Front Genet $6: 230$

Consortium EP (2012) An integrated encyclopedia of DNA elements in the human genome. Nature 489:57-74

Couldrey C, Lee RS (2010) DNA methylation patterns in tissues from mid-gestation bovine foetuses produced by somatic cell nuclear transfer show subtle abnormalities in nuclear reprogramming. BMC Dev Biol 10:27

Daxinger L, Whitelaw E (2010) Transgenerational epigenetic inheritance: more questions than answers. Genome Res 20:1623 $-1628$

De Falco M, Manente L, Lucariello A, Baldi G, Fiore P, Laforgia V, Baldi A, Iannaccone A, De Luca A (2012) Localization and distribution of wolframin in human tissues. Front Biosci (Elite Ed) 4:1986-1998

Ding ZL, Oskarsson M, Ardalan A, Angleby H, Dahlgren LG, Tepeli C, Kirkness E, Savolainen P, Zhang YP (2012) Origins of domestic dog in southern East Asia is supported by analysis of Y-chromosome DNA. Heredity (Edinb) 108:507-514

Dolinoy DC (2008) The agouti mouse model: an epigenetic biosensor for nutritional and environmental alterations on the fetal epigenome. Nutr Rev 66(Suppl 1):S7-S11

Ehrich M, Nelson MR, Stanssens P, Zabeau M, Liloglou T, Xinarianos G, Cantor CR, Field JK, van den Boom D (2005) 
Quantitative high-throughput analysis of DNA methylation patterns by base-specific cleavage and mass spectrometry. Proc Natl Acad Sci USA 102:15785-15790

Eo J, Lee HE, Nam GH, Kwon YJ, Choi Y, Choi BH, Huh JW, Kim M, Lee SE, Seo B, Kim HS (2016) Association of DNA methylation and monoamine oxidase A gene expression in the brains of different dog breeds. Gene 580:177-182

Farre D, Roset R, Huerta M, Adsuara JE, Rosello L, Alba MM, Messeguer X (2003) Identification of patterns in biological sequences at the ALGGEN server: PROMO and MALGEN. Nucleic Acids Res 31:3651-3653

Feil R, Fraga MF (2011) Epigenetics and the environment: emerging patterns and implications. Nat Rev Genet 13:97-109

Freedman AH, Gronau I, Schweizer RM, Ortega-Del Vecchyo D, Han E, Silva PM, Galaverni M, Fan Z, Marx P, Lorente-Galdos B, Beale H, Ramirez O, Hormozdiari F, Alkan C, Vila C, Squire K, Geffen E, Kusak J, Boyko AR, Parker HG, Lee C, Tadigotla V, Wilton A, Siepel A, Bustamante CD, Harkins TT, Nelson SF, Ostrander EA, Marques-Bonet T, Wayne RK, Novembre J (2014) Genome sequencing highlights the dynamic early history of dogs. PLoS Genet 10:e1004016

Fukuda K, Ichiyanagi K, Yamada Y, Go Y, Udono T, Wada S, Maeda T, Soejima H, Saitou N, Ito T, Sasaki H (2013) Regional DNA methylation differences between humans and chimpanzees are associated with genetic changes, transcriptional divergence and disease genes. J Hum Genet 58:446-454

Gainetdinov RR, Caron MG (2003) Monoamine transporters: from genes to behavior. Annu Rev Pharmacol Toxicol 43:261-284

Gaydos LJ, Wang W, Strome S (2014) Gene repression. H3K27me and PRC2 transmit a memory of repression across generations and during development. Science 345:1515-1518 
Germonpre M, Sablin MV, Stevens RE, Hedges REM, Hofreiter M, Stiller M, Despres VR (2009) Fossil dogs and wolves from Palaeolithic sites in Belgium, the Ukraine and Russia: osteometry, ancient DNA and stable isotopes. J Arch Sci 36:473-490

Gregory SG, Connelly JJ, Towers AJ, Johnson J, Biscocho D, Markunas CA, Lintas C, Abramson RK, Wright HH, Ellis P, Langford CF, Worley G, Delong GR, Murphy SK, Cuccaro ML, Persico A, Pericak-Vance MA (2009) Genomic and epigenetic evidence for oxytocin receptor deficiency in autism. BMC Med 7:62

Hannon E, Lunnon K, Schalkwyk L, Mill J (2015) Interindividual methylomic variation across blood, cortex, and cerebellum: implications for epigenetic studies of neurological and neuropsychiatric phenotypes. Epigenetics 10:1024-1032

Harony-Nicolas H, Mamrut S, Brodsky L, Shahar-Gold H, BarkiHarrington L, Wagner S (2014) Brain region-specific methylation in the promoter of the murine oxytocin receptor gene is involved in its expression regulation. Psychoneuroendocrinology 39:121-131

Horvath S, Zhang Y, Langfelder P, Kahn RS, Boks MP, van Eijk K, van den Berg LH, Ophoff RA (2012) Aging effects on DNA methylation modules in human brain and blood tissue. Genome Biol 13:R97

Illingworth RS, Gruenewald-Schneider U, De Sousa D, Webb S, Merusi C, Kerr AR, James KD, Smith C, Walker R, Andrews R, Bird AP (2015) Inter-individual variability contrasts with regional homogeneity in the human brain DNA methylome. Nucleic Acids Res 43:732-744

Jack A, Connelly JJ, Morris JP (2012) DNA methylation of the oxytocin receptor gene predicts neural response to ambiguous social stimuli. Front Hum Neurosci 6:280

Janowitz Koch I, Clark MM, Thompson MJ, Deere-Machemer KA, Wang J, Duarte L, Gnanadesikan GE, McCoy EL, Rubbi L, Stahler 
DR, Pellegrini M, Ostrander EA, Wayne RK, Sinsheimer JS, vonHoldt BM (2016) The concerted impact of domestication and transposon insertions on methylation patterns between dogs and grey wolves. Mol Ecol 25:1838-1855

Jensen P (2015) Adding 'epi-' to behaviour genetics: implications for animal domestication. J Exp Biol 218:32-40

Kato T, Ishiwata M, Yamada K, Kasahara T, Kakiuchi C, Iwamoto K, Kawamura K, Ishihara H, Oka Y (2008) Behavioral and gene expression analyses of Wfs1 knockout mice as a possible animal model of mood disorder. Neurosci Res 61:143-158

Kozlenkov A, Wang M, Roussos P, Rudchenko S, Barbu M, Bibikova M, Klotzle B, Dwork AJ, Zhang B, Hurd YL, Koonin EV, Wegner M, Dracheva S (2016) Substantial DNA methylation differences between two major neuronal subtypes in human brain. Nucleic Acids Res 44:2593-2612

Kukekova AV, Johnson JL, Teiling C, Li L, Oskina IN, Kharlamova AV, Gulevich RG, Padte R, Dubreuil MM, Vladimirova AV, Shepeleva DV, Shikhevich SG, Sun Q, Ponnala L, Temnykh SV, Trut LN, Acland GM (2011) Sequence comparison of prefrontal cortical brain transcriptome from a tame and an aggressive silver fox (Vulpes vulpes). BMC Genomics 12:482

Kusui C, Kimura T, Ogita K, Nakamura H, Matsumura Y, Koyama M, Azuma C, Murata Y (2001) DNA methylation of the human oxytocin receptor gene promoter regulates tissue-specific gene suppression. Biochem Biophys Res Commun 289:681-686

LaPlant Q, Vialou V, Covington HE 3rd, Dumitriu D, Feng J, Warren BL, Maze I, Dietz DM, Watts EL, Iniguez SD, Koo JW, Mouzon E, Renthal W, Hollis F, Wang H, Noonan MA, Ren Y, Eisch AJ, Bolanos CA, Kabbaj M, Xiao G, Neve RL, Hurd YL, Oosting RS, Fan G, Morrison JH, Nestler EJ (2010) Dnmt3a regulates emotional behavior and spine plasticity in the nucleus accumbens. Nat Neurosci 13:1137-1143 
Lesch KP (2007) Linking emotion to the social brain. The role of the serotonin transporter in human social behaviour. EMBO Rep 8:S24 $-\mathrm{S} 29$

Li Y, Vonholdt BM, Reynolds A, Boyko AR, Wayne RK, Wu DD, Zhang YP (2013) Artificial selection on brain-expressed genes during the domestication of dog. Mol Biol Evol 30:1867-1876

Li Q, Wang Y, Hu X, Zhao Y, Li N (2015) Genome-wide mapping reveals conservation of promoter DNA methylation following chicken domestication. Sci Rep 5:8748

Lokk K, Modhukur V, Rajashekar B, Martens K, Magi R, Kolde R, Koltsina M, Nilsson TK, Vilo J, Salumets A, Tonisson N (2014) DNA methylome profiling of human tissues identifies global and tissue-specific methylation patterns. Genome Biol 15:r54

Lowe R, Slodkowicz G, Goldman N, Rakyan VK (2015) The human blood DNA methylome displays a highly distinctive profile compared with other somatic tissues. Epigenetics 10:274-281

Martin DI, Singer M, Dhahbi J, Mao G, Zhang L, Schroth GP, Pachter L, Boffelli D (2011) Phyloepigenomic comparison of great apes reveals a correlation between somatic and germline methylation states. Genome Res 21:2049-2057

Mathelier A, Fornes O, Arenillas DJ, Chen CY, Denay G, Lee J, Shi W, Shyr C, Tan G, Worsley-Hunt R, Zhang AW, Parcy F, Lenhard B, Sandelin A, Wasserman WW (2016) JASPAR 2016: a major expansion and update of the open-access database of transcription factor binding profiles. Nucleic Acids Res 44:D110-D115

McGreevy PD, Georgevsky D, Carrasco J, Valenzuela M, Duffy DL, Serpell JA (2013) Dog behavior co-varies with height, bodyweight and skull shape. PLoS ONE 8:e80529

Mendizabal I, Shi L, Keller TE, Konopka G, Preuss TM, Hsieh TF, Hu E, Zhang Z, Su B, Yi SV (2016) Comparative methylome 
analyses identify epigenetic regulatory loci of human brain evolution. Mol Biol Evol 33:2947-2959

Messeguer X, Escudero R, Farre D, Nunez O, Martinez J, Alba MM (2002) PROMO: detection of known transcription regulatory elements using species-tailored searches. Bioinformatics 18:333-334

Mikeska T, Bock C, El-Maarri O, Hubner A, Ehrentraut D, Schramm J, Felsberg J, Kahl P, Buttner R, Pietsch T, Waha A (2007) Optimization of quantitative MGMT promoter methylation analysis using pyrosequencing and combined bisulfite restriction analysis. J Mol Diagn 9:368-381

Miller CA, Sweatt JD (2007) Covalent modification of DNA regulates memory formation. Neuron 53:857-869

Miller CA, Campbell SL, Sweatt JD (2008) DNA methylation and histone acetylation work in concert to regulate memory formation and synaptic plasticity. Neurobiol Learn Mem 89:599-603

Miller CA, Gavin CF, White JA, Parrish RR, Honasoge A, Yancey CR, Rivera IM, Rubio MD, Rumbaugh G, Sweatt JD (2010) Cortical DNA methylation maintains remote memory. Nat Neurosci 13:664 $-666$

Molaro A, Hodges E, Fang F, Song Q, McCombie WR, Hannon GJ, Smith AD (2011) Sperm methylation profiles reveal features of epigenetic inheritance and evolution in primates. Cell 146:1029 $-1041$

Nakamura K, Sugawara Y, Sawabe K, Ohashi A, Tsurui H, Xiu Y, Ohtsuji M, Lin QS, Nishimura H, Hasegawa H, Hirose S (2006) Late developmental stage-specific role of tryptophan hydroxylase 1 in brain serotonin levels. J Neurosci 26:530-534

Natt D, Rubin CJ, Wright D, Johnsson M, Belteky J, Andersson L, Jensen P (2012) Heritable genome-wide variation of gene expression 
and promoter methylation between wild and domesticated chickens. BMC Genomics 13:59

Neumann ID (2008) Brain oxytocin: a key regulator of emotional and social behaviours in both females and males. J Neuroendocrinol $20: 858-865$

Pai AA, Bell JT, Marioni JC, Pritchard JK, Gilad Y (2011) A genome-wide study of DNA methylation patterns and gene expression levels in multiple human and chimpanzee tissues. PLoS Genet 7:e1001316

Parker HG (2012) Genomic analyses of modern dog breeds. Mamm Genome 23:19-27

Parle-McDermott A, Ozaki M (2011) The impact of nutrition on differential methylated regions of the genome. Adv Nutr 2:463-471

Portela A, Esteller M (2010) Epigenetic modifications and human disease. Nat Biotechnol 28:1057-1068

Ptacek R, Kuzelova H, Stefano GB (2011) Dopamine D4 receptor gene DRD4 and its association with psychiatric disorders. Med Sci Monit 17:RA215-R220

Sandelin A, Alkema W, Engstrom P, Wasserman WW, Lenhard B (2004) JASPAR: an open-access database for eukaryotic transcription factor binding profiles. Nucleic Acids Res 32:D91-D94

Savolainen P, Zhang YP, Luo J, Lundeberg J, Leitner T (2002) Genetic evidence for an East Asian origin of domestic dogs. Science 298:1610-1613

Sherry ST, Ward MH, Kholodov M, Baker J, Phan L, Smigielski EM, Sirotkin K (2001) dbSNP: the NCBI database of genetic variation. Nucleic Acids Res 29:308-311 
Shih JC, Chen K, Ridd MJ (1999) Monoamine oxidase: from genes to behavior. Annu Rev Neurosci 22:197-217

Skinner MK, Guerrero-Bosagna C, Haque MM (2015)

Environmentally induced epigenetic transgenerational inheritance of sperm epimutations promote genetic mutations. Epigenetics 10:762 $-771$

Smith AK, Kilaru V, Klengel T, Mercer KB, Bradley B, Conneely KN, Ressler KJ, Binder EB (2015) DNA extracted from saliva for methylation studies of psychiatric traits: evidence tissue specificity and relatedness to brain. Am J Med Genet B 168B:36-44

Smith TA, Martin MD, Nguyen M, Mendelson TC (2016) Epigenetic divergence as a potential first step in darter speciation. Mol Ecol 25:1883-1894

Solnica-Krezel L, Sepich DS (2012) Gastrulation: making and shaping germ layers. Annu Rev Cell Dev Biol 28:687-717

Sommer-Trembo C, Bierbach D, Arias-Rodriguez L, Verel Y, Jourdan J, Zimmer C, Riesch R, Streit B, Plath M (2016) Does personality affect premating isolation between locally-adapted populations? BMC Evol Biol 16:138

Szyf M (2011) DNA methylation, the early-life social environment and behavioral disorders. J Neurodev Disord 3:238-249

Thalmann O, Shapiro B, Cui P, Schuenemann VJ, Sawyer SK, Greenfield DL, Germonpre MB, Sablin MV, Lopez-Giraldez F, Domingo-Roura X, Napierala H, Uerpmann HP, Loponte DM, Acosta AA, Giemsch L, Schmitz RW, Worthington B, Buikstra JE, Druzhkova A, Graphodatsky AS, Ovodov ND, Wahlberg N, Freedman AH, Schweizer RM, Koepfli KP, Leonard JA, Meyer M, Krause J, Paabo S, Green RE, Wayne RK (2013) Complete mitochondrial genomes of ancient canids suggest a European origin of domestic dogs. Science 342:871-874 
Thierry-Mieg D, Thierry-Mieg J (2006) AceView: a comprehensive cDNA-supported gene and transcripts annotation. Genome Biol 7 (Suppl 1):S12 11-14

Thompson TM, Sharfi D, Lee M, Yrigollen CM, Naumova OY, Grigorenko EL (2013) Comparison of whole-genome DNA methylation patterns in whole blood, saliva, and lymphoblastoid cell lines. Behav Genet 43:168-176

Turner BM (2009) Epigenetic responses to environmental change and their evolutionary implications. Philos Trans R Soc Lond B Biol Sci 364:3403-3418

Unternaehrer E, Luers P, Mill J, Dempster E, Meyer AH, Staehli S, Lieb R, Hellhammer DH, Meinlschmidt G (2012) Dynamic changes in DNA methylation of stress-associated genes (OXTR, BDNF) after acute psychosocial stress. Transl Psychiatry 2:e150

Unternaehrer E, Meyer AH, Burkhardt SC, Dempster E, Staehli S, Theill N, Lieb R, Meinlschmidt G (2015) Childhood maternal care is associated with DNA methylation of the genes for brain-derived neurotrophic factor (BDNF) and oxytocin receptor (OXTR) in peripheral blood cells in adult men and women. Stress 18:451-461

Vage J, Bonsdorff TB, Arnet E, Tverdal A, Lingaas F (2010) Differential gene expression in brain tissues of aggressive and nonaggressive dogs. BMC Vet Res 6:34

Varley KE, Gertz J, Bowling KM, Parker SL, Reddy TE, Pauli-Behn F, Cross MK, Williams BA, Stamatoyannopoulos JA, Crawford GE, Absher DM, Wold BJ, Myers RM (2013) Dynamic DNA methylation across diverse human cell lines and tissues. Genome Res 23:555-567

Verzijden MN, ten Cate C, Servedio MR, Kozak GM, Boughman JW, Svensson EI (2012) The impact of learning on sexual selection and speciation. Trends Ecol Evol 27:511-519 
Vila C, Amorim IR, Leonard JA, Posada D, Castroviejo J, PetrucciFonseca F, Crandall KA, Ellegren H, Wayne RK (1999) Mitochondrial DNA phylogeography and population history of the grey wolf canis lupus. Mol Ecol 8:2089-2103

vonHoldt BM, Pollinger JP, Lohmueller KE, Han E, Parker HG, Quignon P, Degenhardt JD, Boyko AR, Earl DA, Auton A, Reynolds A, Bryc K, Brisbin A, Knowles JC, Mosher DS, Spady TC, Elkahloun A, Geffen E, Pilot M, Jedrzejewski W, Greco C, Randi E, Bannasch D, Wilton A, Shearman J, Musiani M, Cargill M, Jones PG, Qian Z, Huang W, Ding ZL, Zhang YP, Bustamante CD, Ostrander EA, Novembre J, Wayne RK (2010) Genome-wide SNP and haplotype analyses reveal a rich history underlying dog domestication. Nature 464:898-902

Walton E, Hass J, Liu J, Roffman JL, Bernardoni F, Roessner V, Kirsch M, Schackert G, Calhoun V, Ehrlich S (2016)

Correspondence of DNA methylation between blood and brain tissue and its application to schizophrenia research. Schizophr Bull 42:406 $-414$

Wang GD, Zhai W, Yang HC, Wang L, Zhong L, Liu YH, Fan RX, Yin TT, Zhu CL, Poyarkov AD, Irwin DM, Hytonen MK, Lohi H, Wu CI, Savolainen P, Zhang YP (2016) Out of southern East Asia: the natural history of domestic dogs across the world. Cell Res 26:21 $-33$

Wayne RK, vonHoldt BM (2012) Evolutionary genomics of dog domestication. Mamm Genome 23:3-18

Weinshilboum RM, Otterness DM, Szumlanski CL (1999) Methylation pharmacogenetics: catechol O-methyltransferase, thiopurine methyltransferase, and histamine N-methyltransferase. Annu Rev Pharmacol Toxicol 39:19-52

Xing Y, Shi S, Le L, Lee CA, Silver-Morse L, Li WX (2007) Evidence for transgenerational transmission of epigenetic tumor susceptibility in Drosophila. PLoS Genet 3:1598-1606 
Yu NK, Baek SH, Kaang BK (2011) DNA methylation-mediated control of learning and memory. Mol Brain 4:5

http://eproofing.springer.com/journals/printpage.php?token=9TJDw81DY5-Mtt0ArK... 2017.03.20. 